\title{
Case Report of Unilateral Variations in Testicular and Renal Vessels: A Morphological and Clinical Study
}

\author{
Sávio Siqueira, ${ }^{1}$ Eduardo Seubert Coelho Vieira, ${ }^{2}$ Isabel Fusaro Aguiar Oliveira, ${ }^{2}$ Mariana Trindade Tofani, ${ }^{2}$ Pedro Henrique \\ Marques Pereira²
}

'United States

${ }^{2}$ School of Medicine Faculdade de Ciências Médicas de Minas Gerais, Minas Gerais, Brazil

Disclose and conflicts of interest: none to be declared by all authors

\section{ABSTRACT}

Introduction: some variations have already been found in the origin, number and path of the testicular arteries, without consensus about their rates. Among the alternative origins, the accessory renal arteries are the ones described with the greatest recurrence. In this article we report a case of unilateral origin of the testicular artery from an inferior renal polar artery. We also analyze the prevalence and clinical/surgical importance of this kind of variation.

Material and Methods: during routine dissection, vascular anatomical variations were found close to the right kidney of a male adult's corpse. Such findings led to an investigation of the prevalence and clinical/surgical significance of this type of variation.

Results: the right kidney was supplied by three arteries. One entered the renal hilum and the other two were inferior polar arteries, anterior and posterior to the ureter. The anterior vessel arched over the testicular vein and originated the testicular artery. In contrast, there were not any vascular variations on the left side.

Conclusion: the knowledge of variations such as the one detailed above is important for the planning of surgeries and the correct diagnosis of affections regarding the renal hilum and the testicles.

Keywords: Anatomical variation; Testicular artery; Inferior renal polar artery

\section{Introduction}

Testicular arteries are described as paired visceral branches of the abdominal aorta. ${ }^{1}$ They generally originate from the anterolateral aspect of this vessel at the level of the second lumbar vertebra, slightly below the renal arteries. They descend obliquely under the peritoneum, anteriorly to the psoas major muscle, pass through the deep inguinal ring, become a content of the spermatic cord, and end in the testicles, irrigating them., ${ }^{1,2}$

In some cases, namely variations are found in the origin, number and path of those arteries. There is no consensus in literature about the variation rates: Pai et al (2008) registered 10 anomalous arteries in 34 cadavers $\left(14.7 \%\right.$ of the total number of arteries), ${ }^{3}$ Asala et al (2001) reported variations exclusively on the right side of 7 out of 150 corpses $(4,7 \%$ of the total number of cadavers) ${ }^{4}$ Çiçekcibaşi et al (2002) registered variations in the origin of 14 out of the 90 evaluated testicular arteries, ${ }^{5}$ Mamatha et al. (2015) found differences in $20 \%$ of the cases, while studying 40 cadavers. $^{6}$

Regarding alternative origins of those vessels, the following arteries can be cited: renal, middle suprarenal, common iliac, internal iliac, inferior epigastric, lumbar and accessory renal. ${ }^{6}$ The accessory renal arteries are the ones described with greatest recurrence. ${ }^{1}$ They are supernumerary arteries destined to the kidneys, being considered the most common clinically important renal vascular variation. ${ }^{7}$ Generally, they originate from the abdominal aorta or the iliac arteries. Other origins, although rare, include the inferior part of the thoracic aorta and the lumbar and mesenteric arteries. Most accessory renal arteries proceed to the hilum or to the renal poles. Those that reach the poles are designated inferior or superior, according to the pole they supply. The terminology used in literature varies: some authors consider that the accessory arteries are just the ones that proceed to the hilum, whereas the polar arteries should be called aberrant, on account of getting into the renal substance directly. ${ }^{7-9}$

The knowledge of these vascular variations is necessary for the appropriate planning of procedures such as renal transplantation, urological and testicular operations. ${ }^{6}$ Furthermore, since the anomalous vessels can be associated with hydronephrosis, sterility or orthostatic albuminuria, being aware of their existence has proven to be of great importance. ${ }^{10,11}$

The present article describes a case of unilateral origin of the testicular artery from an inferior polar artery and provides an analysis of the prevalence and clinical importance of this kind of variation. 


\section{Case Report}

During routine dissection at the Anatomy Laboratory of Faculdade de Ciências Médicas de Minas Gerais, the abdominal cavity was opened and the retroperitoneal structures were exposed. After the removal of the connective tissue around the testicular and renal vessels, their origin and course were evaluated. The variations found were recorded and photographed.

The right kidney was supplied by three arteries (Figs. 1 and 2). The first entered the renal hilum following the renal vein, the second ran anterior to the ureter and entered the inferior kidney pole and the third passed behind the ureter and entered the same pole. Both polar arteries emerged from the ventral aspect of the aorta passing in front of the inferior vena cava in their path to the kidneys (Fig. 2). The distance between them was $2.5 \mathrm{~cm}$, and the posterior vessel had an inferior position. The origin of the anterior artery (length of $6 \mathrm{~cm}$ ) was in line with the left testicular artery, while the posterior artery (length of $7 \mathrm{~cm}$ ) arose at the same level as the inferior mesenteric artery (Fig. 2).

The right testicular artery was a branch of the anterior inferior polar artery. Its distance from the aorta was $2 \mathrm{~cm}$. The anterior inferior polar artery arched over the right testicular vein and this vein followed the testicular artery and drained into the confluence of the renal vein and the inferior vena cava.

The left kidney and the left testicle did not present any noticeable vascular variations (Fig. 1). The renal and testicular arteries arose from the aorta and the testicular vein drained into the renal vein as usual.

It is important to notice that no similar variation has ever been recorded by the institution, in the period of 2008-2016, when 112 (a hundred and twelve) cadavers were dissected.

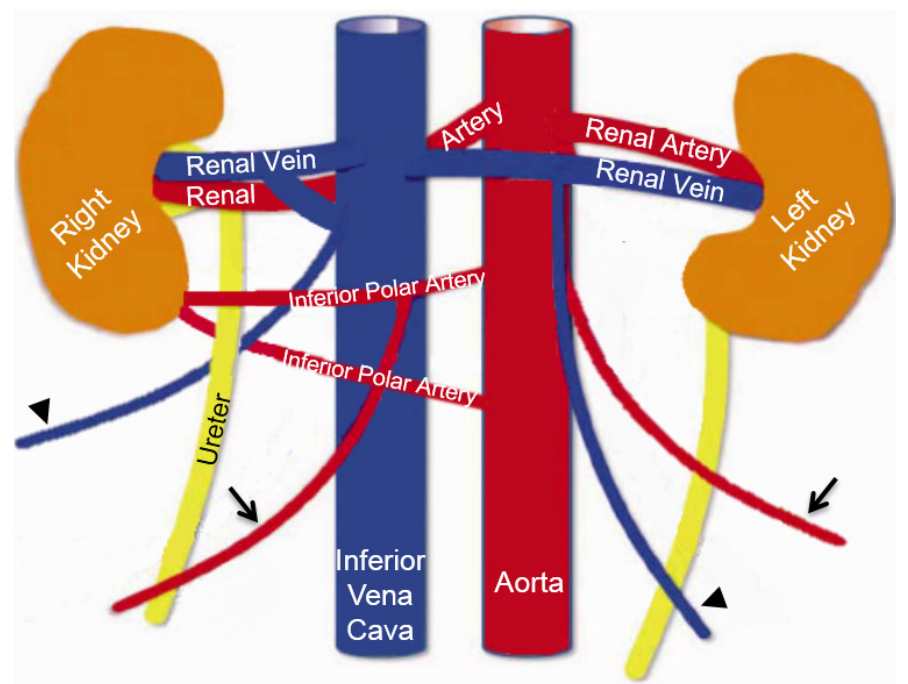

Figure 1. Sketch of the kidney and related vascular structures with anatomical variations. The arrows point to the testicular arteries, while the arrow heads point to the testicular veins. Note that only the left testicular artery originates from the aorta, while the right one emerges from an inferior polar artery.

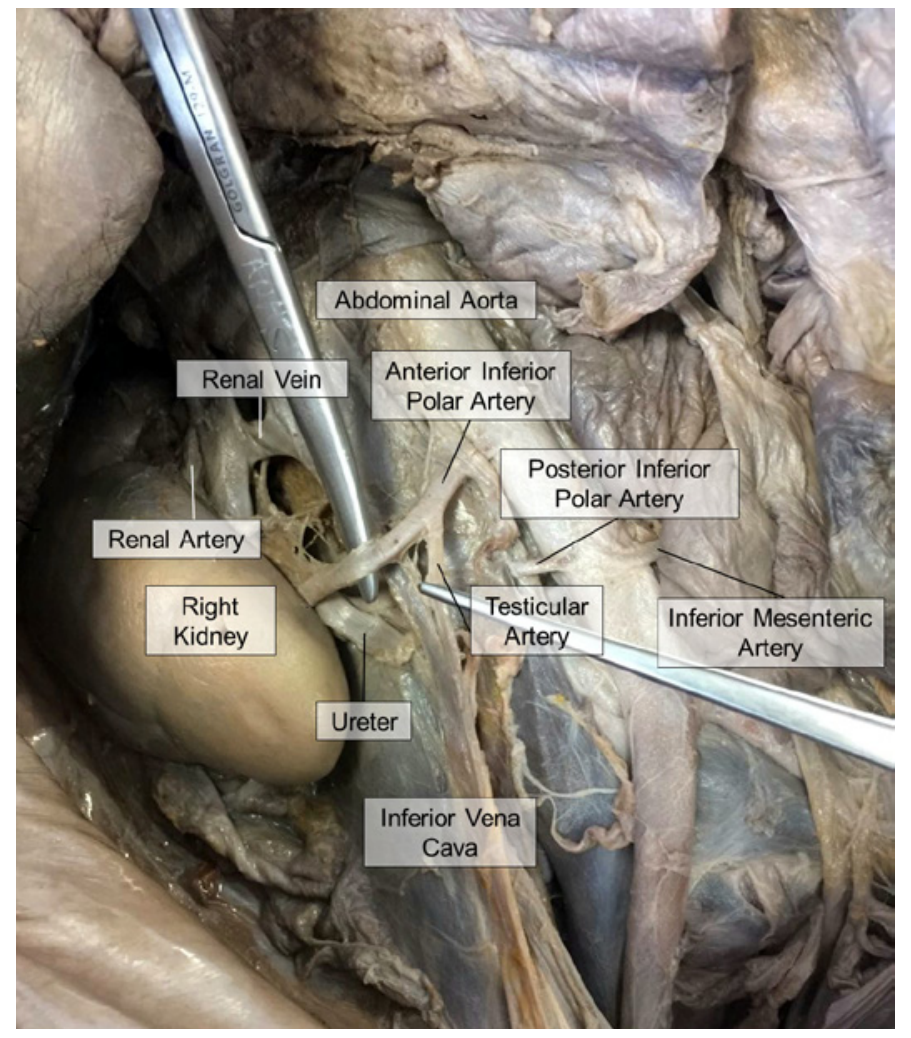

Figure 2. General view of the right renal pedicle and the ipsilateral testicular vessels.

\section{Discussion}

Variations of the testicular arteries are attributed to anomalies in embryological development.,11 The kidneys and the gonads come from the intermediary mesoderm and receive a blood supply derived from the lateral mesonephric branches of the dorsal aorta. These branches are divided into three groups: a cranial one (first and second arteries, proximal to the celiac trunk and posterior to the adrenal glands), an intermediate one (third to fifth arteries, which proceed on the ventral surface of the adrenal glands) and a caudal one (sixth to ninth arteries, which also follows the ventral surface of the adrenal glands).,12

In the majority of cases, only a single artery from the intermediate group persists, originating the renal artery. The conservation of more than one artery leads to the development of supernumerary renal arteries, such as the inferior polar ones. ${ }^{6}$ Testicular arteries, for instance, usually derive from the caudal group. According to Çiçekcibaşi et al (2002), it would be the anomalous origin from the intermediate group that would lead to the so called 'Type II' variation in the gonadal artery's origin, which means, an origin from a renal artery (regular or supernumerary). ${ }^{5}$ In the studied cadaver, the presence of an inferior polar artery and of the Type II variation in the gonadal artery leads to the conclusion that a combination of both processes happened during embryogenesis.

In terms of prevalence, supernumerary kidney 
arteries occur in 25 to $30 \%$ of the general population..$^{13}$ 30.76 to $47.3 \%$ arise from the aorta and 12.2 to $12.82 \%$ are branches of the renal arteries. ${ }^{14,15}$ Kornafel et al (2010) reported that out of 8 studies, 5 found a preponderance of these vessels on the left side and the others found the right side to be the dominant. ${ }^{16}$ Among the variations, the upper (superior) polar artery occurs in 4.3 to $7 \%$ of kidneys (3.3 to $7.5 \%$ percent of cases), while the inferior is found in 3 to $10.8 \%$ percent of kidneys or $10 \%$ of patients. ${ }^{16}$

Variations in the testicular arteries are less common, with rates ranging from 4.7 to $20 \%$. Concerning the alternative origins of these vessels, Shoja et al (2007) described the main or accessory renal artery in $14 \%$ of the cases. In their study, the origin from an inferior polar artery, just as in the present case, was the most common finding (7\%). ${ }^{17}$ Petru et al (2007) found a higher prevalence, with $5 / 16$ cases of origin from an accessory renal artery. ${ }^{2}$ Çiçekcibaşi et al (2002), meanwhile, reported only $5.5 \%$ of arteries with this origin, $2.2 \%$ on the right (same side as in the analyzed corpse) and 3.3\% on the left side. ${ }^{5}$

Analyzing these numbers, it is possible to notice that, among the variations of the renal and testicular vessels, the most common pattern is of supernumerary renal arteries originating from the aorta and penetrating the lower pole of the left kidney, with testicular arteries originating from the inferior polar renal artery. Although the studied cadaver largely complies with this standard, it is possible to notice that the findings were on the right side and that there was not only one accessory renal artery, but two, with a pattern of distribution without any equivalent in other reports.

From a clinical point of view, the knowledge of these variations is extremely relevant. Inferior polar arteries that, like in the described cadaver, cross the ureteropelvic junction may compromise the urine flow and lead to hydronephrosis. ${ }^{10}$ Furthermore, when these vessels arch over the testicular vein, as the anterior inferior polar artery of the present case, they may lead to varicocele and sterility or may be a cause of orthostatic albuminuria. ${ }^{11}$

Moreover, the presence of more than one renal artery makes the kidneys not recommended for transplant procedures owing to the difficulty in the realization of multiple anastomoses, the longer ischemic time and the higher rate of post-transplant renal failure (when inferior polar arteries are present, the failures are due to vascular thrombosis). ${ }^{14,18}$

In aortic surgery, dissection of the abdominal aorta can result in vascular injury of any accessory renal vessel that has not been identified. A troublesome bleeding may occur. The avulsion of an anomalous gonadal artery arising from the supernumerary renal artery is also possible. ${ }^{1}$

During renal and retroperitoneal procedures, it is also important to identify supernumerary renal arteries. Since they are terminal vessels, their accidental ligature can lead to ischemia and necrosis of the kidney area that they supply. ${ }^{15,19}$ In addition, when lower polar arteries are present they tend to give important arterial supply to the upper ureter, consequently any occlusion or inadvertent ligation can result in necrosis at the ureteropelvic junction. ${ }^{20}$

The presence of a gonadal artery originated from the inferior polar renal artery may lead to its injury during the percutaneous treatment of ureteropelvic junction obstruction. The injury of this artery is usually followed by major bleeding with the need of embolization. That is why in such cases the retroperitoneal approach may be a better option. ${ }^{2}$

Anomalous gonadal arteries also pose a danger during total or partial nephrectomies and renal transplants. As these vessels are the only vascular supply to the gonads, injury during renal procedures can cause testicular atrophy. ${ }^{6}$

For all this reasons, adequate preparation for any procedures regarding the renal hilum region is crucial. Therefore, radiologists and surgeons must be familiar with the possibility of variations such as the ones found in this study and arteriography or Doppler ultrasound must be performed before any intervention near or involving the renal hilum.

\section{Conclusion}

Not many anatomical variations like the ones described in this study have been published, even though renal and testicular arteries anomalies have, in fact, been presented in the literature. The effects of this variation in vivo are not clear yet, albeit possible implications are predictable through the study of medical procedures and the anatomy related to them.

The anatomy of renal and testicular vessels is important in renal and testicular surgeries, as well as in any procedure near the renal hilum. It is also related to genitourinary pathologies such as hydronephrosis and sterility. The knowledge of variations such as the one detailed in this article is important to plan procedures and to correctly diagnose affections.

In this context, arteriography or Doppler ultrasound examination of the renal hilum, prior to any surgical procedure within the region is of real relevance. 


\section{References}

1. Panagouli E, Lolis E, Venieratos D. Bilateral Origin of the Testicular Arteries from the Lower Polar Accessory Renal Arteries. Int J Morphol 2012;30(4):1316-1320.

2. Petru B, Elena S, Dan I, Constantin D. The morphology and the surgical importance of the gonadal arteries originating from the renal artery. Surg Radiol Anat 2007;29(5):367-371 PubMed.

3. Pai MM, Vadgaonkar R, Rai R, et al. A cadaveric study of the testicular artery in the South Indian population. Singapore Med J 2008;49(7):551-555.

4. Asala S, Chaudhary SC, Masumbuko-Kahamba N, Bidmos M. Anatomical variations in the human testicular blood vessels. Ann Anat 2001;183(6):545-549.

5. Ciçekcibaşi AE, Salbacak A, Şeker M, Ziylan T, Büyükmumcu $M$, Uysal ii. The origin of gonadal arteries in human fetuses: anatomical variations. Ann Anat 2002;184(3):275-279.

6. H M, D'Souza AS, P V, Ray B, Suhani, Pallavi; H. M. A Cadaveric Study about the Anomolous Origin of Testicular Arteries Arising from the Accessory Renal Arteries. Indian J Surg 2015;77(2):111-116 10.1007/ s12262-012-0737-8 (Removed).

7. Tarzamni MK, Nezami N, Rashid RJ, Argani H, Hajealioghli P, Ghorashi S. Anatomical differences in the right and left renal arterial patterns. Folia Morphol (Warsz) 2008;67(2):104-110 PubMed.

8. Aristotle S, Sundarapandian, Felicia C. Anatomical study of variations in the blood supply of kidneys. J Clin Diagn Res 2013;7(8):1555-1557.

9. Budhiraja V, Rastogi R, Anjankar V, Babu CSR, Goel P. Supernumerary renal arteries and their embryological and clinical correlation: a cadaveric study from north India. ISRN Anat 2013;2013:405712 10.5402/2013/405712(Removed.

10. Shoja MM, Tubbs RS, Shakeri A, Ardalan MR, Rahimi-Ardabili B, Ghabili K. Asymptomatic bilateral ureteropelvic junction obstruction due to supernumerary renal arteries. Saudi J Kidney Dis Transpl 2008;19(5):806-808.
11. Singh R, Jaiswal A, Shamal SN, Singh SP. Variation in the origin of the testicular arteries and drainage of the right testicular vein. Int J Morphol 2011;29(2):614-616.

12. Paraskevas GK, Ioannidis 0 , Raikos A, et al. High origin of a testicular artery: a case report and review of the literature. J Med Case Reports 2011;5(1):75.

13. VonAchen P, Hamann J, Houghland T, et al. Accessory renal arteries: Prevalence in resistant hypertension and an important role in nonresponse to radiofrequency renal denervation. Cardiovasc Revasc Med 2016;17(7):470-473.

14. Budhiraja V, Rastogi R, Asthana AK. Variant origin of superior polar artery and unusual hilar branching pattern of renal artery with clinical correlation. Folia Morphol (Warsz) 2011;70(1):24-28.

15. Talović E, Kulenović A, Voljevica A, Kapur E. Review of the supernumerary renal arteries by dissection method. Acta Med Acad 2007;36(2):59-69.

16. Kornafel O, Baran B, Pawlikowska I, Laszczyński P, Guziński M, Sąsiadek M. Analysis of anatomical variations of the main arteries branching from the abdominal aorta, with 64-detector computed tomography. Pol J Radiol 2010;75(2):38-45.

17. Shoja MM, Tubbs RS, Shakeri AB, Oakes WJ. Origins of the gonadal artery: embryologic implications. Clin Anat 2007;20(4):428-432.

18. Mir NS, Ul Hassan A, Rangrez R, et al. Bilateral Duplication of Renal Vessels: Anatomical, Medical and Surgical perspective. Int J Health Sci (Qassim) 2008;2(2):179-185.

19. Verma P, Arora AK, Sharma P, Mahajan A. Variations in branching pattern of renal artery and arrangement of hilar structures in the left kidney: clinical correlations, a case report. Ital J Anat Embryol 2012;117(2):118-122.

20. Johnson PB, Cawich SO, Shah SD, et al. Accessory renal arteries in a Caribbean population: a computed tomography based study. Springerplus 2013;2(1):443.
Received: November 23, 2018

Accepted: January 28, 2020
Corresponding author

Sávio Siqueira

saviolanasiqueira@gmail.com 